\title{
Dynamic Stability of a Seaplane in Take-Off
}

Laurent Dala ${ }^{12}$

Council for Scientific and Industrial Research, Pretoria 0001, South Africa

University of Pretoria, Pretoria 0002, South Africa

This research is based on the investigation into the dynamic stability associated with seaplanes during take-off. Various forces acting on a hydroplaning hull form have been empirically defined. Such empirical data have shown that under a certain set of conditions, a hydroplaning hull will begin to porpoise, an instability oscillation in both the vertical direction, and about the centre of gravity In order to investigate the porpoising motion, a shallow water flume was used. It was the first time that such facility has been used to simulate the dynamic motion of hydroplaning hull forms. An experimental method derived from the store release experiments was derived for the dynamics measurements. The equipment developed has led to an analysis of a flat plate hull porpoising in a supercritical channel. The porpoising limit has then been very well defined.

\section{Nomenclature}

$$
\begin{aligned}
& L_{T}=\text { wetted length of transom, } \mathrm{m} \\
& L_{K}=\text { wetted length of keel, } \mathrm{m} \\
& \lambda_{1}=\text { pressure wetted length to beam ratio } \\
& F_{B}=\text { buoyant force, } \mathrm{N} \\
& \rho \quad=\text { density, } \mathrm{kg} / \mathrm{m}^{3} \\
& \mathrm{~V}=\text { displaced volume, } \mathrm{m}^{3} \\
& v_{f}=\text { fluid velocity, } \mathrm{m} / \mathrm{s} \\
& v_{W}=\text { wave velocity, } \mathrm{m} / \mathrm{s} \\
& v_{B} \quad=\quad \text { body velocity, } \mathrm{m} / \mathrm{s}
\end{aligned}
$$

${ }^{1}$ Professor and R\&D Manager, Aeronautic Systems Competency (ASC), Meiring Naudé Road, Brumeria, Pretoria 0001, South Africa; LDala1 @ csir.co.za, MAIAA.

${ }^{2}$ Industrial CSIR Chair in Aeronautical Engineering, Department of Mechanical and Aeronautical Engineering, Hatfield, Pretoria 0002, South Africa. 


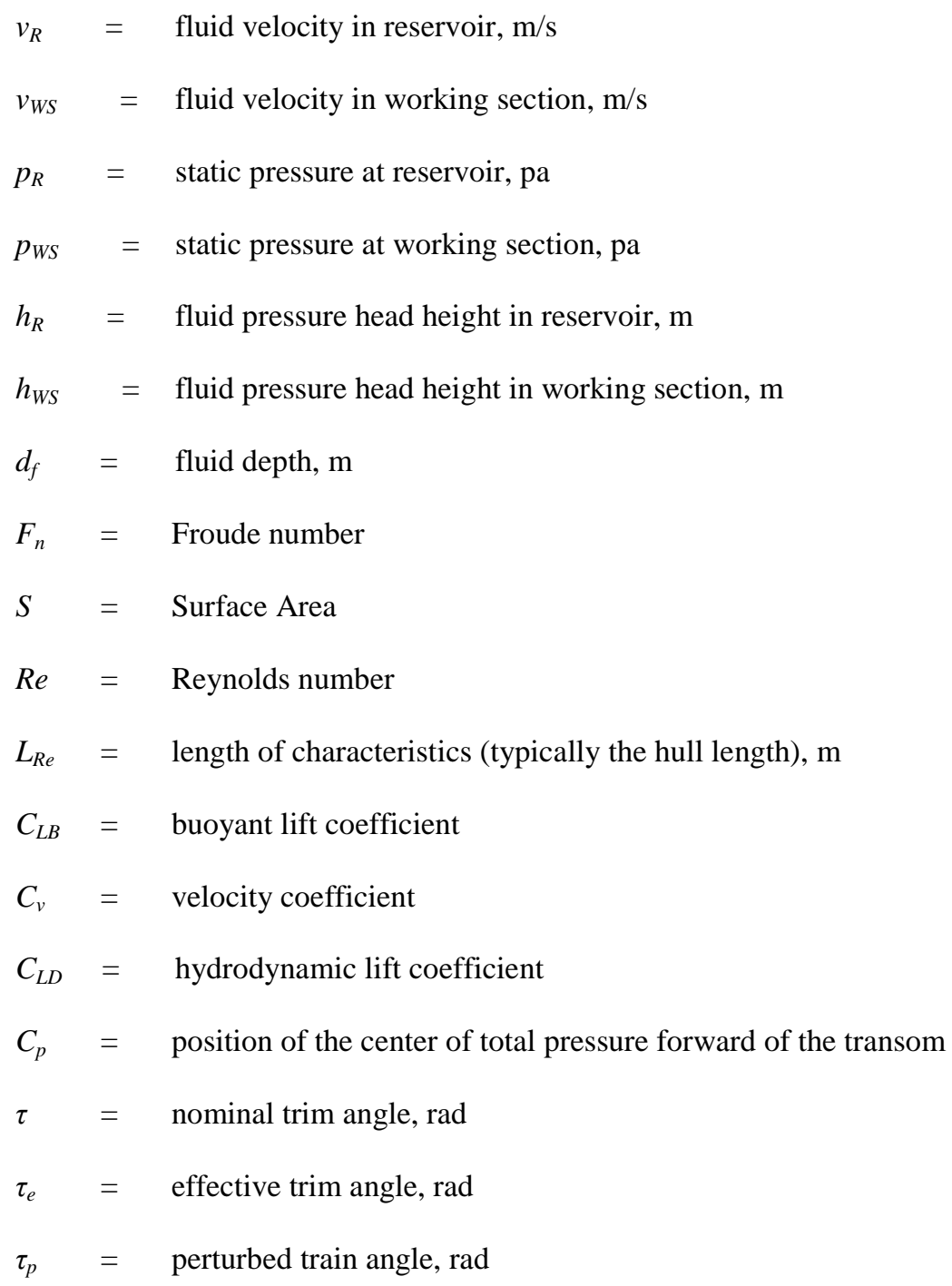

\section{Introduction}

With rising costs of fuel and growing concerns over the environment, seaplanes are becoming an interesting alternative forms of transport. But as described by Stout in [1, 2], the hydrodynamic stability prediction is of great importance in the design of seaplanes. Porpoising is a major issue in the design of seaplanes [3-5]. The towing tank is still the main experimental facility used to model the porpoising as described in [3].

In order to investigate the dynamic motion of hydroplaning hull forms a shallow water flume has been modified and used. To perform the experiment, it was necessary to record the motion of the model. At the small scale this has been performed at, weight was crucial, and therefore any recording devices had to be as unobtrusive as possible. It was then decided to adapt the store release tracking system based on video to determine the hull's motion. The 
effect of mass on the frequency of oscillation was enlightened using the shallow water flume. The general trend showed the frequency of oscillation to decrease as mass increases. The heave and pitch amplitude were also determined in function of the flow velocity. This research has shown that the vicinity in which sustained porpoising was achieved using a shallow water flume was within the same approximate vicinity as that established in [5].

\section{Hydrodynamic Motion}

In 1932, Perring \& Glauert [4] presented a mathematical approach to study the dynamics of seaplanes experiencing the planing effect. From this work, planing theory has developed. But one of the most prominent studies into hydroplaning hull forms was performed by Savitsky in [5]. His work resulted in a set of empirical equations being defined that allow a prismatic planning hull to be designed to particular performance requirement, and is still a staple of speed boat design today.

During hydroplaning, there are two forces supporting the weight of the hull; buoyancy and dynamic pressure. With each of these forces, there can be an associated center of pressure. With buoyancy this is the center of static pressure, and with dynamic forces, the center of hydrodynamic pressure. Savitsky in [5] assumed that for small angles of attack, the horizontal centre of buoyancy is $33 \%$ of the wetted length forward of the transom. Assuming that only buoyancy acts on the hull, this would be the point about which no moment due to hydrostatic forces would be applied. It is therefore reasonable to resolve all buoyant forces through this point. Fig. 1 reproduced the centre of dynamic pressure acts at a point $75 \%$ forward of the transom.

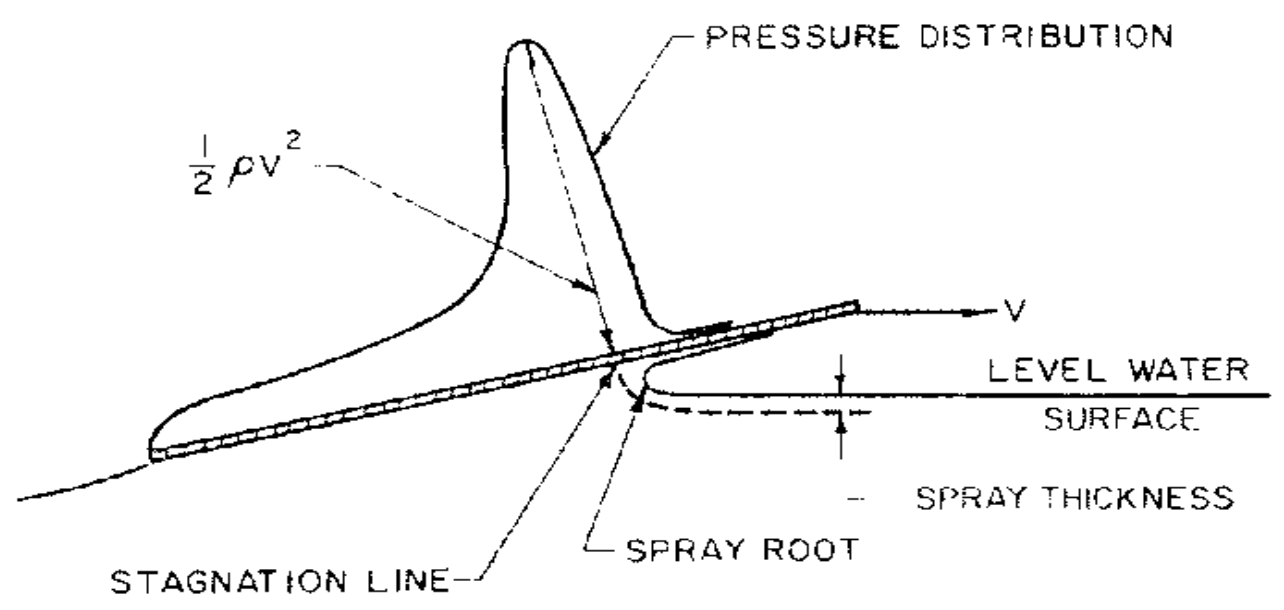

Fig. 1 Pressure Distribution on a Flat Plate [5] 
As the vessel increases speed, the dominance of forces changes from hydrostatic to hydrodynamic. In [5-7], a formula was derived by taking moments for both hydrostatic and hydrodynamic components about the transom. By dividing through by the total load on the water, the position of the centre of total pressure can be found. By studying existing hydroplaning data, a relationship between the position of the centre of pressure and the wetted length to beam ratio could be established. The resultant equation is shown below.

$$
C_{p}=0.75-\frac{1}{5.21 \frac{C_{v}^{2}}{l^{2}}+2.39}
$$

This equation can be represented as a graph for different values of wetted length to beam ratio. This has been described in $[5,8]$ in Fig. 2.

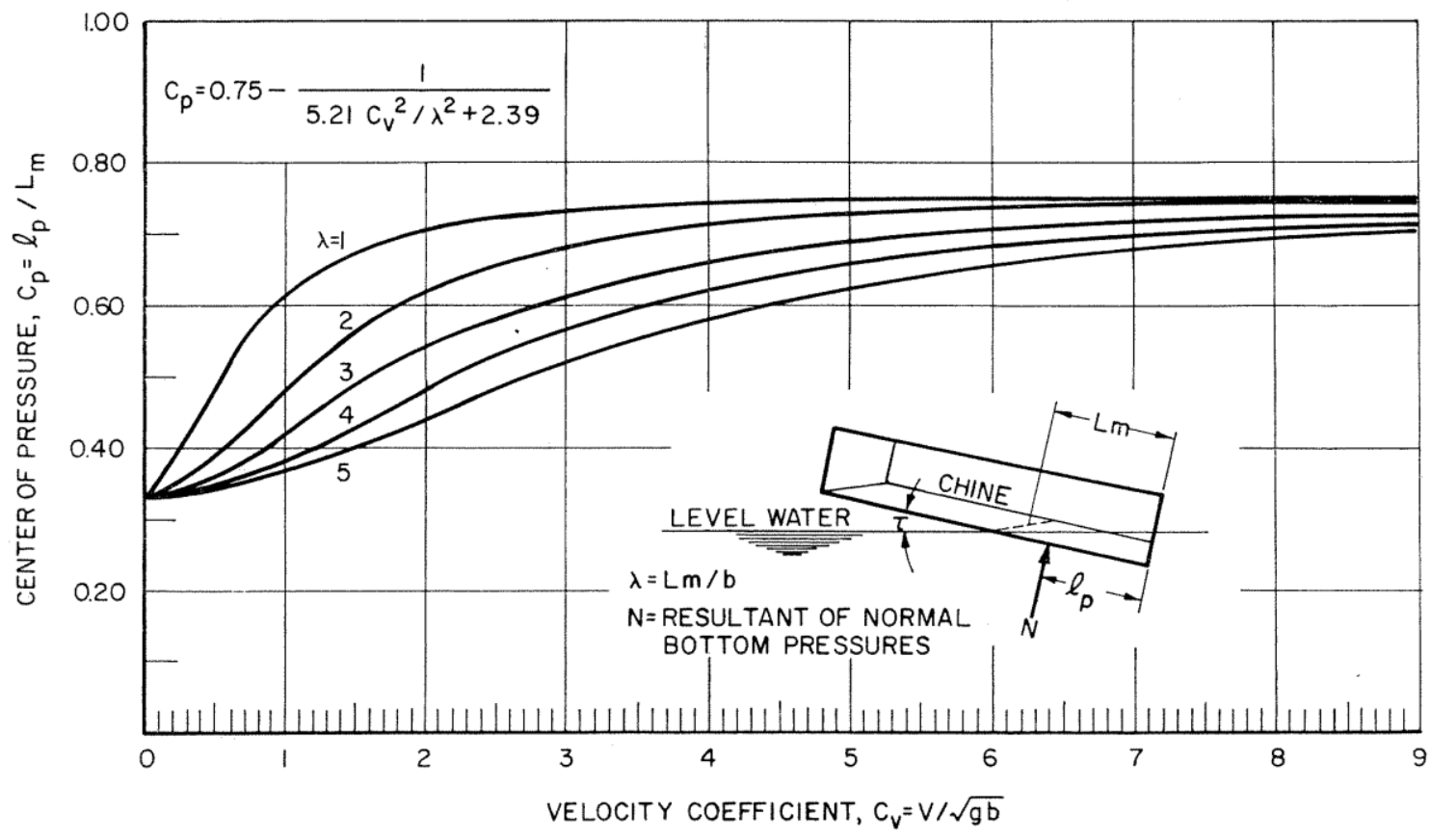

Fig. 2 Centre of Pressure Position against Velocity Coefficient [5]

Fig. 2 shows that as the velocity coefficient increases, the centre of pressure moves from the centre of buoyancy to the centre of hydrodynamic pressure, i.e. from $33 \%$ to $75 \%$. This does assume however, a fixed draught and trim angle. In a dynamic environment, both the draught and trim angle can change, resulting in a change in wetted length and lift coefficient. 
An instability regime unique to hydroplaning hulls can be experienced under certain conditions. This dynamic instability is known as porpoising. When a hull is porpoising, it is oscillating in both pitch and heave. This can happen even in calm water, and the motion can be neutrally stable, continuing at steady amplitude, or unstable, with the amplitude increasing.

Porpoising can inflict considerable structural damage to a hydroplaning hull. Under extreme conditions, this may result in the hull leaving the water, and returning at negative trim angles, causing the hull to submarine as described in $[8,9]$. It is therefore important to understand the problem.

Typical research has referred so far to a porpoising stability limit - a set of conditions that once exceeded, will allow a vessel to porpoise. In [9-11] the porpoising phenomenon associated with seaplane floats was investigated. Similar experiments performed in $[12,13]$ showed that the limit of porpoising stability could be written in terms of the velocity coefficient, the lift coefficient and the trim angle. Work presented in [14-16] consolidated much of the information and developed a set of design tools that allow the porpoising stability of a hull to be estimated by designers. Fig. 3 shows their work presented in graphical form.

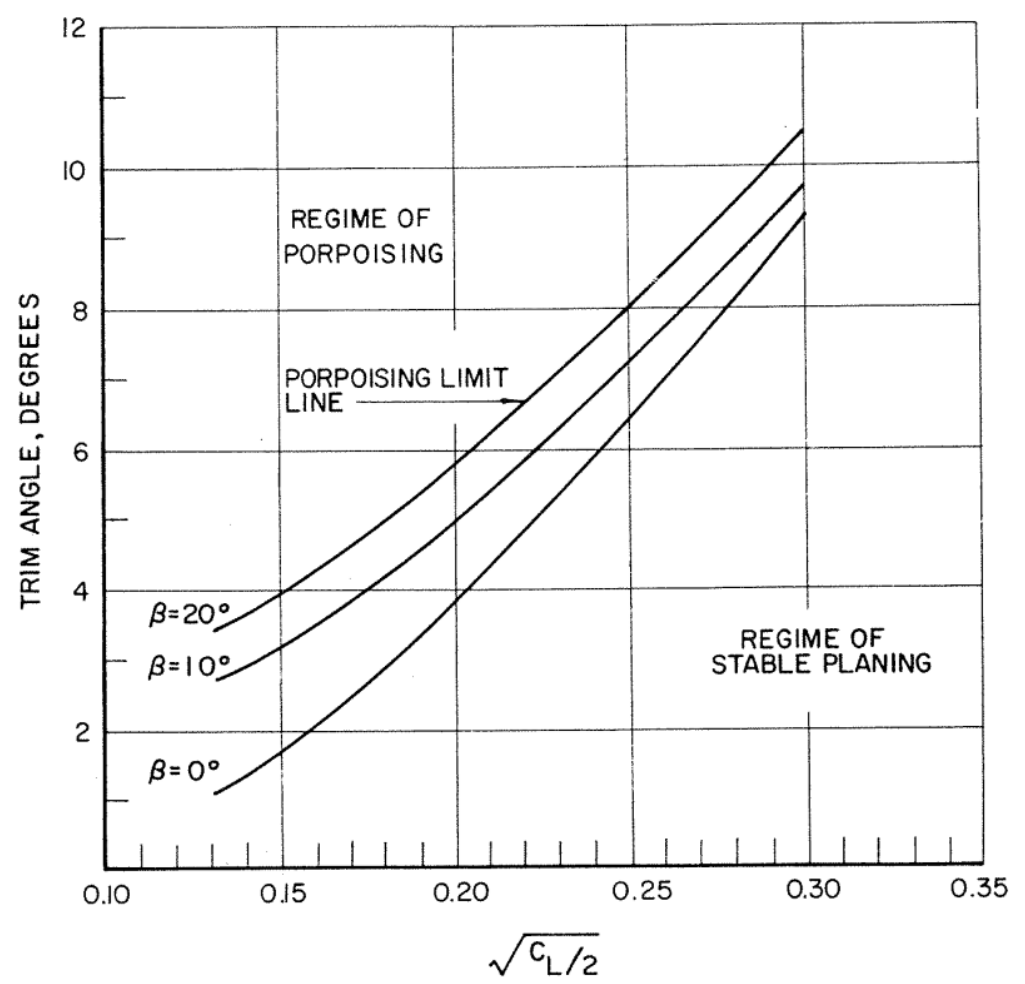

Fig. 3 Porpoising Stability Limit [14] 
The lines in the graph represent the porpoising limit for each deadrise angle. If, for a given deadrise angle, the combination of lift coefficient and trim angle are above the line, then the vessel will tend to porpoise. If a vessel is porpoising, the attitude must be changed such that the trim angle reduces as described in [5]. Note also that increasing deadrise angle allows a higher trim angle to be exploited without inducing porpoising characteristics.

In [12-14] conducted numerous experiments were conducted in porpoising and discovered that increasing or decreasing the polar moment of inertia did not change the position or shape of these curves; porpoising still began to exist at the same conditions. The characteristic frequency of the motion does however change, with frequency decreasing with an increase in polar moment of inertia.

\section{Experimental Method}

\section{A. Flume Testing}

In order to investigate the forces acting on a hydroplaning hull, an experiment was devised that allows the relationships between various hull forms to be studied. Traditionally, ships and waterborne aircraft have been tested using towing tanks. These tanks are necessarily long, and therefore expensive. They are also few and far between, and due to their operational nature there is a limited amount of time available for the collection of data, reduced even further once the settling time for the experiment is allowed for.

By comparison, hydraulic flumes are considerably smaller for the same working cross section, cheaper to construct and more commonplace. Also, an experiment can be run indefinitely, the limit being up to the engineer. Drawbacks associated with a flume are the effects of surface wave interference and more importantly, the effects that the water energy level have on the wave system inherent with the tests, all of which interfere with results. Fig. 4 shows an example of a flume.

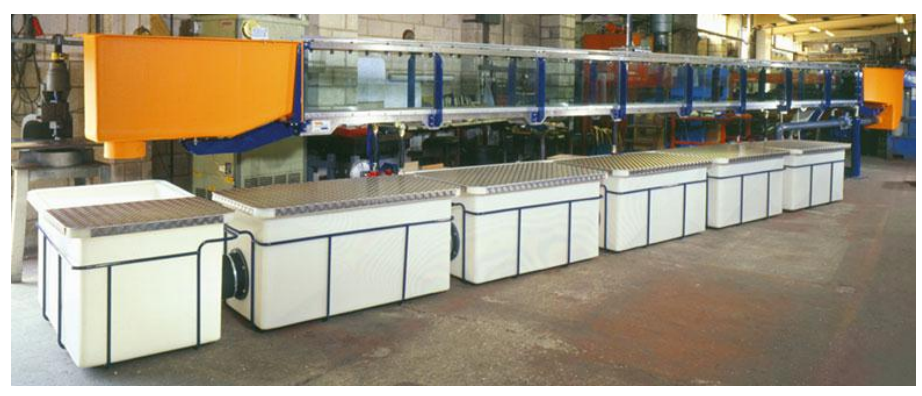

Fig. 4 Typical Layout of a Flume 
One of the differences between a towing tank and a flume is that there is a Froude number associated with the flow of water through an open channel. In the field of Hydraulics, this is known as the depth Froude number, and relates the velocity of wave propagation to the velocity of the water flow, as shown Eq. (2).

$$
F_{n_{d}}=\frac{v_{f}}{\sqrt{g d_{f}}}
$$

This form of the Froude number can be used to define the flow regime of the fluid. If the depth Froude number exceeds unity, then the flow velocity is greater than the wave propagation velocity, and is labelled as supercritical. A depth Froude number below unity describes subcritical flow, where wave propagation velocity exceeds the flow velocity. When the fluid flow velocity is equal to the wave propagation velocity, the flow is known as critical. The Froude number at this point is known as the critical Froude number, and occurs when the fluid is at a depth known as the critical depth.

To model a hydroplaning hull operating above its critical Froude number, the flume had to be capable of achieving supercritical flow. This required the construction of a new working section that allows fluid Froude number to be controlled. In order to achieve supercritical flow in a more or less horizontal channel, a pressure head must be maintained upstream of the working section. In the open channel flume this was done by use of an undershot weir at the start of the working section. A sloped gate enabled the depth of water in the working section, and therefore its velocity and Froude number to be varied. The dimensions for this working section were dependent on the volume flow rate that the pump was capable of producing. The specification for the working section is shown in Table 1.

Table 1 Properties of the Flume

\begin{tabular}{|l|c|}
\hline Volume Flow Rate $Q$ & $0.0124 \mathrm{~m}^{3} / \mathrm{s}$ \\
\hline Working Section Width $\mathrm{w}$ & $150 \mathrm{~mm}$ \\
\hline Dam Height & $260 \mathrm{~mm}$ \\
\hline Minimum Depth at $\mathrm{Q}_{\max }$ & $41 \mathrm{~mm}$ \\
\hline Maximum Depth at $\mathrm{Q}_{\max }$ & $150 \mathrm{~mm}$ \\
\hline Critical Depth & $89 \mathrm{~mm}$ \\
\hline Minimum Velocity at $\mathrm{Q}_{\max }$ & $0.55 \mathrm{~m} / \mathrm{s}$ \\
\hline Maximum Velocity at $\mathrm{Q}_{\max }$ & $2.02 \mathrm{~m} / \mathrm{s}$ \\
\hline Critical Velocity & $0.93 \mathrm{~m} / \mathrm{s}$ \\
\hline
\end{tabular}

This yields a maximum depth Froude number of 2.17 . 


\section{B. Modelling the Flume}

With dynamic modelling of the hull form required, it was useful to understand how an accelerating velocity would affect the performance. This requires that the flume be capable of time dependent response. To do this, it was necessary to understand the transient period the flume's operation undergoes before a steady state condition is reached.

\section{Defining the Model}

When the flume was initially switched on, a wave of water proceeded from the inlet, through the working section, to the outlet. The water level then steadily rose until it reaches the height of the weir. From this point on, the pressure head of the water in the top reservoir increased. Since the weir was set at a particular height, the level only rose upstream of the weir. This in turn caused an increase in velocity downstream of the weir, through the working section. This continued until steady state equilibrium is reached.

In order to understand this phenomenon further, the Bernoulli's Law was applied to the flume, as shown Eq. (3)

$$
p_{R}+\frac{1}{2} \rho v_{R}^{2}+\rho g h_{R}=p_{W S}+\frac{1}{2} \rho v_{W S}^{2}+\rho g h_{W S}
$$

There is a volume flow rate associated with the working section. During steady state operation, this is equivalent to the volume flow rate entering the reservoir. However, during the transient phase, this is not the case. The volume flow rate through the working section can be calculated by applying Bernoulli's equation to obtain the velocity. This velocity can then be applied to the continuity equation to find the volume flow rate.

If the volume flow rate from the pump to the reservoir exceeds that through the working section, this will result in a net increase in volume on the reservoir side. Since the plan form area of the reservoir is constant, this manifests itself in an increase in depth.

The flume can be modelled as a quasi-steady state model, in the same way the hull was. By assuming that conditions remain constant across a discrete time period, Bernoulli and the continuity law can be applied. By iterating this across an appropriate time span, the dynamic response of the model can be determined. Fig. 5 shows the model, as a velocity response to being switched on at full power. 


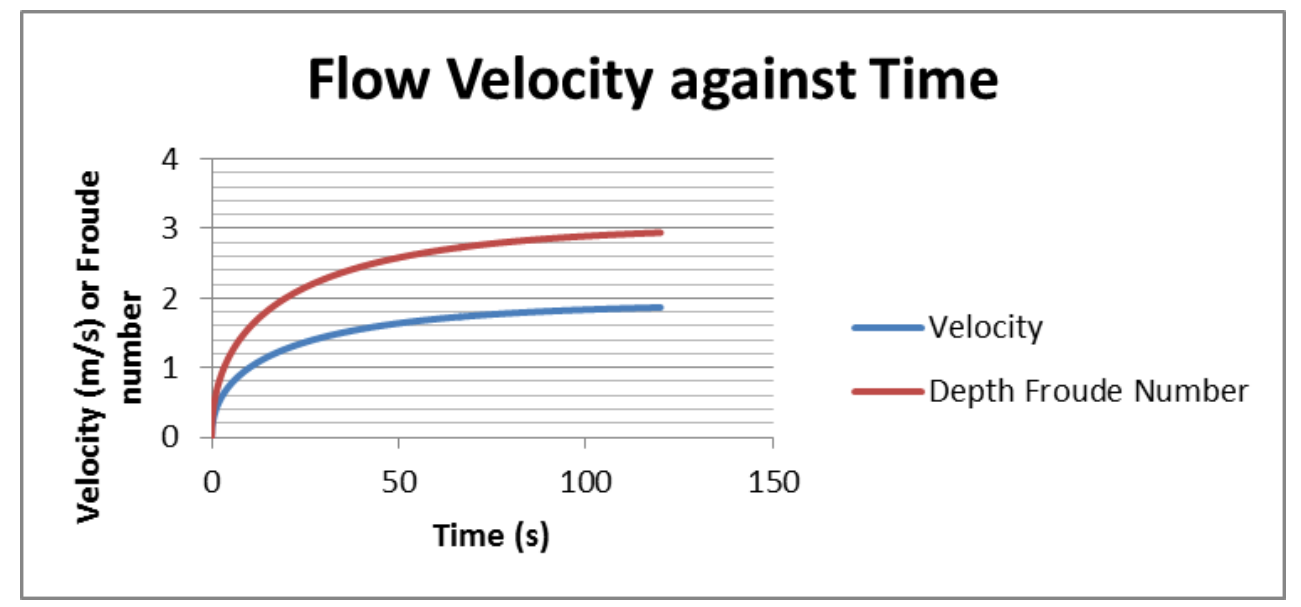

Fig. 5 Froude Number and Velocity against Time for Flume Working Section

\section{Validating the Model}

To determine whether the model was performing accurately or not, an experiment was performed to validate it. The experiment was to use the same initial conditions as represented in Fig. 5, i.e. switched on at full power. One of the limitations of the flume is its inability to record the instantaneous flow velocity at any point. In order to avoid problems of comparing the velocities, the experiment was focus on comparing the depth in the reservoir section. Since the depth and the velocity are related by Eq. (3), validating the response of the model in terms of depth also validated its response in terms of velocity. A comparison of the model and the experiment is shown in Fig. 6.

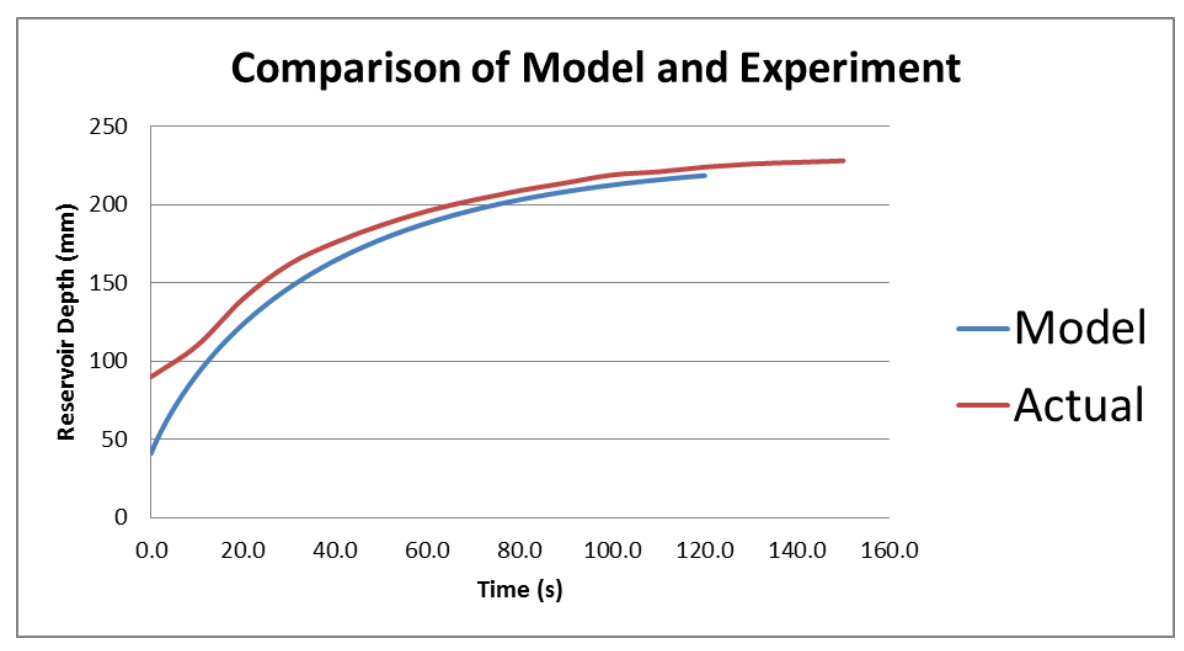

Fig. 6 Comparison between Flume Model and Experimental Data 
Fig. 6 shows a very good correlation between experiment and model. There are a few fluctuations in the first few samples. This is believed to be due to the measurement of waves. It was found when the flume is first turned on, as it fills, a slight wave reflects off the working section, and oscillates up and down the reservoir. By taking more than one height reading at each interval, an average could have been found, which may have negated this problem.

It can also be seen that there is a slight discrepancy between model and experiment across the whole range. It is believed that part of this is due to the difficulty of judging exactly when the water level reaches the gate, and so initiating the stop watch introduces a degree of human error. If the results were modified to eliminate this source of error, the discrepancy between model and experiment would be less.

That being said, the experimental results do show a tendency towards a slightly higher depth than the model does. This could well be due to the fact that friction is not accounted for in the model. Friction would have the effect of causing the fluid velocity to slow a little. Since Bernoulli's theory states a form of conservation of energy, this reduction in velocity would manifest itself in the form of an increase in pressure head, hence the additional depth noted with the experiment.

\section{Dynamic Balance}

The primary purpose of the experiments is to measure and track the motion of various hull configurations in the flume. In addition to creating the correct conditions in the flume, a method of mounting the model is required. For this, a dynamic balance is necessary.

\section{Equipment Requirements}

In order to fill the role effectively, there are a number of requirements the balance must fulfil. The primary purpose of the balance is to allow motion in certain directions whilst constraining it in others, such as

- Allow motion of the hull in the heave direction.

- Allow motion of the hull in the pitch axis.

- Constrain the hull from motion in the yaw axis.

- Constrain the hull from motion in the transverse direction.

- Constrain the hull from motion in the roll axis.

- Constrain the hull from fore and aft motion. 
In addition to the primary dynamic requirements of the balance, there are those associated with its operation that the balance must be designed to accommodate if the primary requirements are to be met effectively. These are listed here:

- The weight of the sting must be kept to a minimum to reduce its effect on the model's weight.

- The balance must have enough adjustment built in to cope with water depths between $40 \mathrm{~mm}$ and 200mm.

- The effects of friction in any joints or slides must be minimised.

- Rotational inertia in any radius arms must be kept to a minimum to avoid its impact on the model's mass.

- It must be simple to mount alternative hull models to the balance.

\section{Balance Design}

The balance design is based around a series of sliders. A graphite tube sliding on a steel rod provides the means of locating the model in the vertical axis. To prevent the model yawing, a tail arm with a steel fork locates a second steel slide.

To keep weight down, structural parts were made from balsa wood, since it has very low density and a high resistance to buckling. This allows a light weight, structural part.

To accommodate motion in the vertical direction, graphite tubes on a steel rod were employed. The steel rod is attached to the base of the balance. Any loads are then transferred from the graphite slides to the base of the balance. The graphite ensures a low friction contact whilst the steel ensures structural rigidity, without incurring a weight penalty on the moving parts.

To prevent rotation around the steel rod, a trailing arm was mounted to the balance. This trailing arm has a steel fork mounted to the rear of it, which in turn slides on a second steel rod. This prevents the hull rotating in the yaw direction.

The steel rods were mounted to a laser cut acrylic base. This base has multiple mounting points on it so that its height above the water can be adjusted. To accommodate motion of the model in pitch, a pivot was mounted to the balance. To reduce friction and weight, the pivot is a very slender plain bearing, of 0.7 mm diameter. To this pivot was mounted a shoe, which in turn mounted directly to the model. 
Fig. 7 shows the balance, standing alone on the left, and on the right assembled to its carrier frame. The small foot that the hull model mounts to can be seen at the lower extremity of the balance.
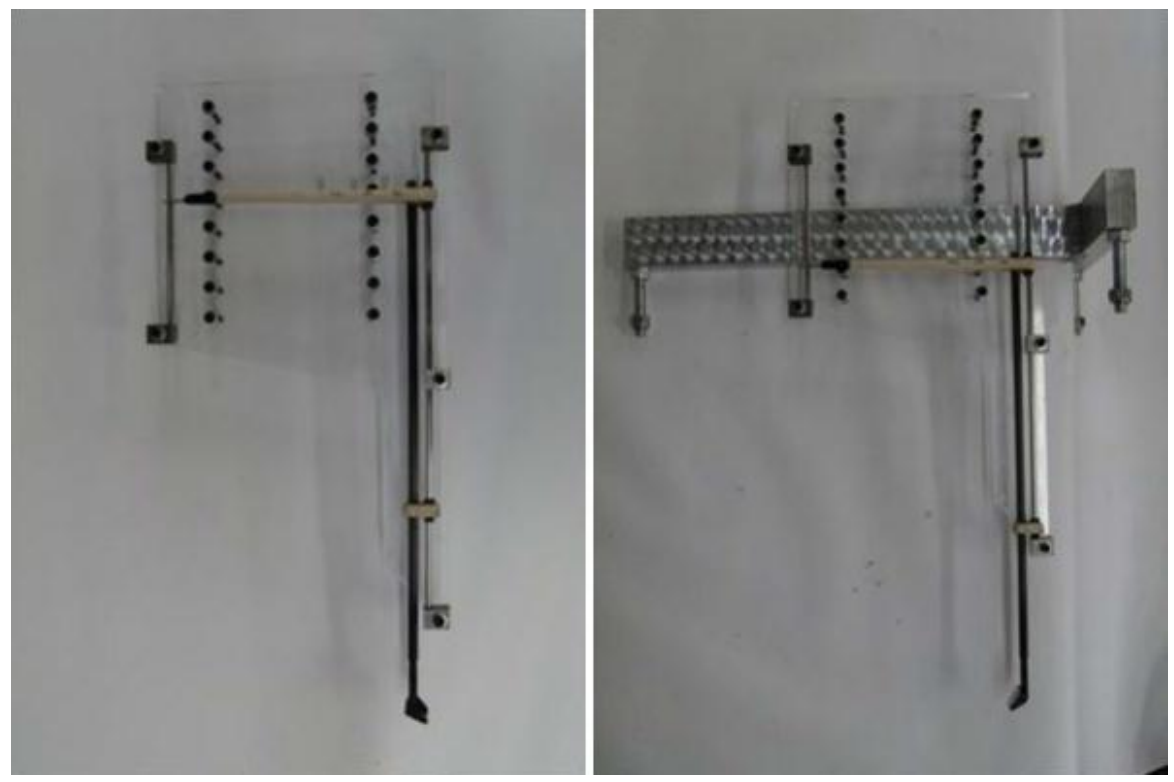

Fig. 7 Dynamic Balance

\section{Hull Model}

In order to get accurate measurements in dynamic motion, the hull has to be light weight and also presents the correct hydrodynamic geometry.

The condition being modelled is for a chines-dry situation. This requires that the water film leave the hull cleanly where the bottom meets the topsides.

These are the two major requirements of the hull form. To maintain a low hull weight, the hull was hotwired from blue foam manually using a jig. The outline was first formed to achieve the correct hydrodynamic shape. Initial testing showed that although a prismatic hull form is desirable, it would be prudent to design it with a hydrodynamic bow. When the experimental conditions have been reached, this bow is clear of the water and does not interfere with the flow. However, during the start-up process as the flume fills, the bow prevents the model from digging in, and thus saving both it and the balance from damage. Fig. 8 shows the hull mounted to the dynamic balance. 


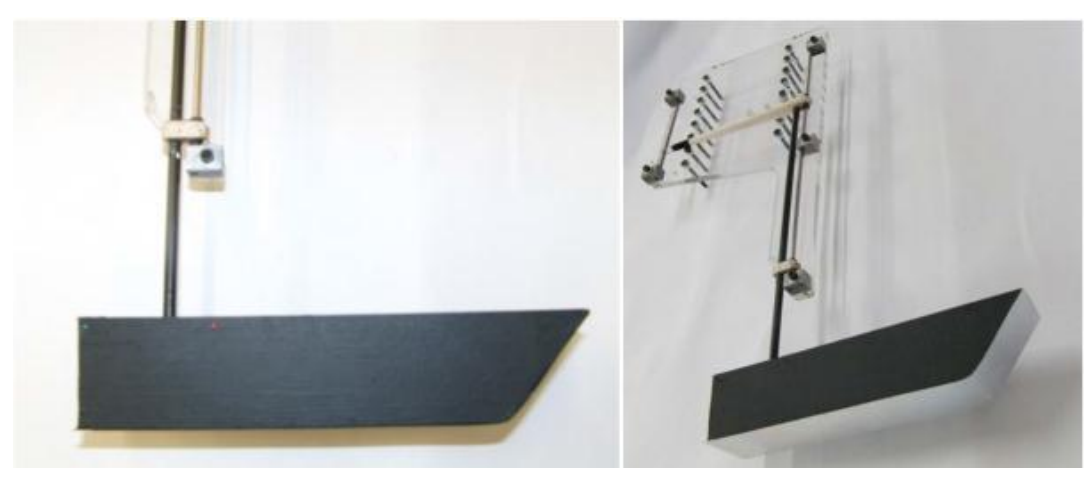

Fig. 8 The Hull mounted to the Balance

\section{E. Data Acquisition}

The experiment method developed for the dynamic measurements of the hull was derived from the store separation freedrop analysis used in wind tunnels as described in [17].

Freedrop studies are made by realizing or ejecting dynamically scaled store models from a parent aircraft installed in a wind tunnel. The separation characteristics are determined from either high speed motion camera or multiple exposure still photographs taken from two or three locations.

The store separation freedrop was then adapted to record the dynamic motion of the hull model. At the small scale this was being performed at, weight of the hull model is crucial, and therefore any recording devices have to be as unobtrusive as possible. Video recording offers the least intrusive method of capturing the model's motions, and thus would reduce any errors associated with increasing the mass of the model or interference with its motion due to flying leads or data cables to various other sensors.

There are two basic processes in the use of video capture to provide the required information. The first is to record the actual motion. This is done with a video camera, which produces a series of frames in a set time sequence, and provides the raw data used for analysis.

The second part is in analyzing the footage. Since the position of the model can be measured in each frame, it is possible to derive positions with respect to the time frame of the video, yielding velocities and from there, accelerations. By combining these two processes, the hull's motion can be tracked. 
To record the raw footage, a camera was required. The precision of the test is dependent on two of the camera's parameters. For positional accuracy within each frame, the size of the frame is important. A higher resolution allows a greater positional accuracy to be obtained in each frame.

In addition to the accuracy associated with the two dimensions in each frame, there would be a requirement for accuracy in the time dimension. A higher frame rate allows greater precision in the sampling time step that allows the motion to be tracked more accurately.

Since porpoising is an oscillatory motion, a high frame rate is desirable. If the oscillation were to occur at a rate comparable to the frame rate of the camera, the results may be misleading due to aliasing.

To this end, a machine vision camera was used. The camera is a Blue Cougar S-121C. Its specifics are listed in Table 2.

Table 2 Camera Specifications

\begin{tabular}{|c|c|c|}
\hline \multicolumn{3}{|l|}{ Available sensors } \\
\hline Model name & \multicolumn{2}{|c|}{ mvBlueCOUGAR -121 } \\
\hline Model variant & $\begin{array}{l}\text { G } \\
\text { Gray }\end{array}$ & $\begin{array}{l}\text { C } \\
\text { Color }\end{array}$ \\
\hline Densor supplier & \multicolumn{2}{|c|}{ Sony } \\
\hline Densor name & \multicolumn{2}{|c|}{ ICX204AL/AQ } \\
\hline Sensor type & \multicolumn{2}{|c|}{ CCD } \\
\hline D Sensor diagonal in [mm] & \multicolumn{2}{|c|}{6} \\
\hline - Indication of lens category to be used & \multicolumn{2}{|c|}{$1 / 3^{\prime \prime}$} \\
\hline $\begin{array}{l}\text { Desolution of sensor's active } \\
\text { area (width } \mathrm{x} \text { height in [pixels]) }\end{array}$ & \multicolumn{2}{|c|}{$1024 \times 768$} \\
\hline D Pixel size (width $\mathrm{x}$ height in [ $\mu \mathrm{m}]$ ) & \multicolumn{2}{|c|}{$4.65 \times 4.65$} \\
\hline Deadout type & \multicolumn{2}{|c|}{ Progressive } \\
\hline D Transfer/shutter type & \multicolumn{2}{|c|}{ Full Frame } \\
\hline D Maximum frame rate [Hz] & \multicolumn{2}{|c|}{39} \\
\hline Dxposure (step width) & \multicolumn{2}{|c|}{$50 \mu \mathrm{s}-10 \mathrm{~s}(1 \mu \mathrm{s})$} \\
\hline
\end{tabular}

Fig. 9 shows the camera mounted to the tripod at the side of the flume. The working section can also be seen as can the balance's mounting shoe. The black background is to reduce reflections. The angled aluminum plate on the right is the sluice gate. When the experiment is actually running, a black paper shroud is placed all around the flume to reduce reflections. 


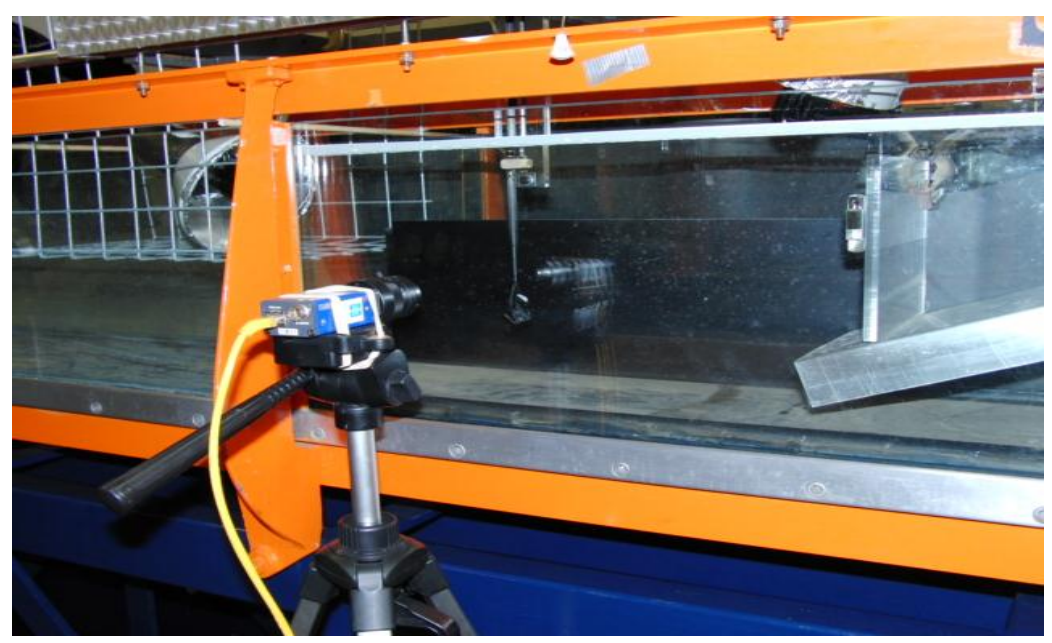

Fig. 9 Experimental Layout

\section{EXPERIMENTAL RESULTS}

After performing the experiment, the video footage was post processed using the simulink model developed. This gives a series of simulations showing the various parameters' oscillations against time, for each of these experiments.

\section{A. Effect on Oscillation of Centre of Gravity and Mass}

Fig. 10 shows the effect of mass on the frequency of oscillation. Each data set represents a different longitudinal centre of gravity position, defined in millimeters from the hull's transom. It can be seen that the general trend shows the frequency of oscillation to decrease as mass increases. It can also be seen that the gradient of this descent is more pronounced the further forward the center of gravity is.

The results are for the Centre of Gravity at 50mm are more uniform than the other two centres of gravity tested, and have a more defined correlation. 


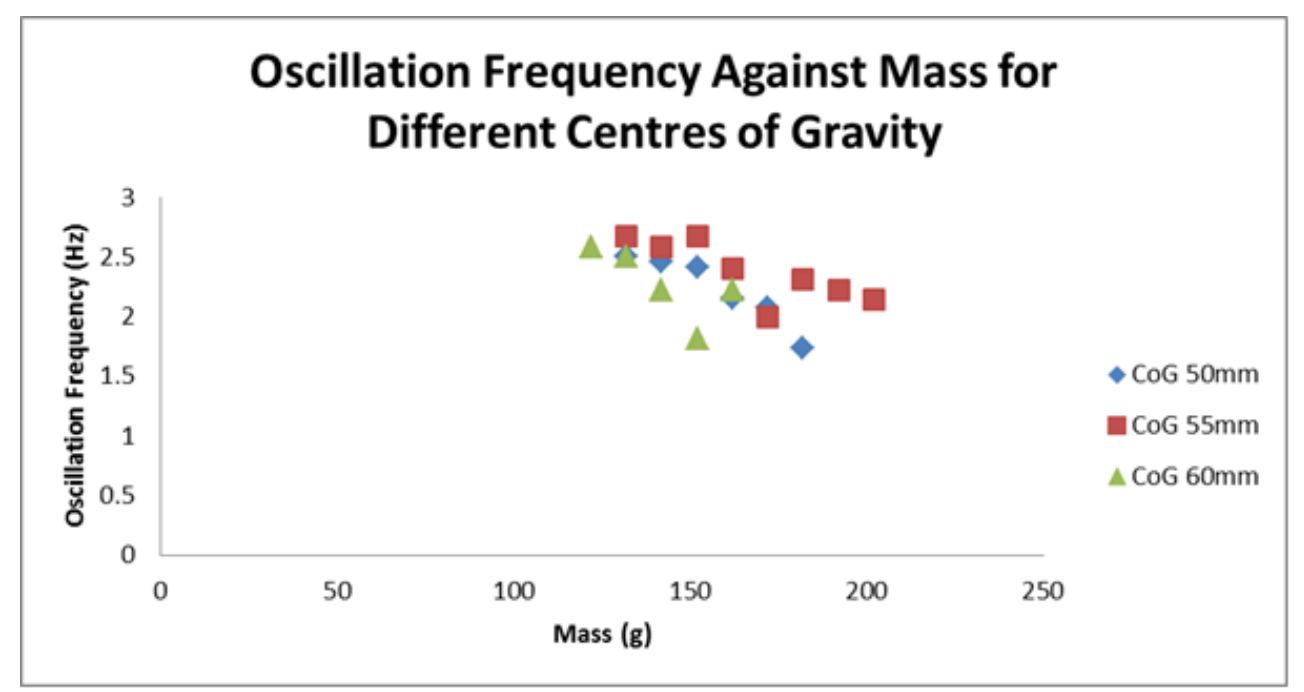

Fig. 10 Oscillation Frequency against Mass for Different Centres of Gravity

In addition to the frequency, the amplitudes of oscillation in both pitch and heave can be found with respect to the mass. Fig. 11 shows the amplitude of pitch oscillation with changing mass at different Centers of Gravity.

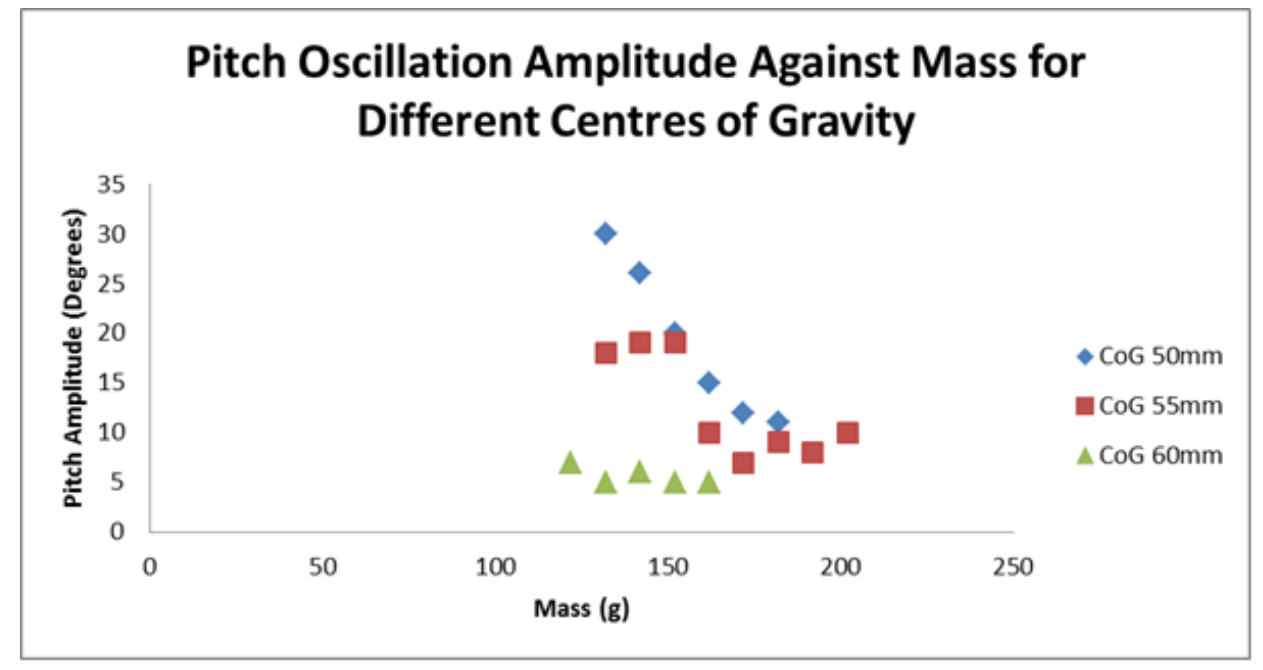

Fig. 11 Pitch Oscillation Amplitude against Mass for Different Centres of Gravity

Again, it can be seen that the most uniform and best correlation is obtained when the centre of gravity is furthest back. The graph shows that amplitude decreases with increasing mass, and that the effect is more pronounced the further back the centre of gravity is. For the furthest forward centre of gravity at $60 \mathrm{~mm}$, the graph is almost horizontal, denoting very little change in amplitude with change in mass. Again, the poorest correlation appears to 
be from the data where the Centre of Gravity is at $55 \mathrm{~mm}$. The amplitude of heave motion against mass shows very similar characteristics. Fig.12 shows this.

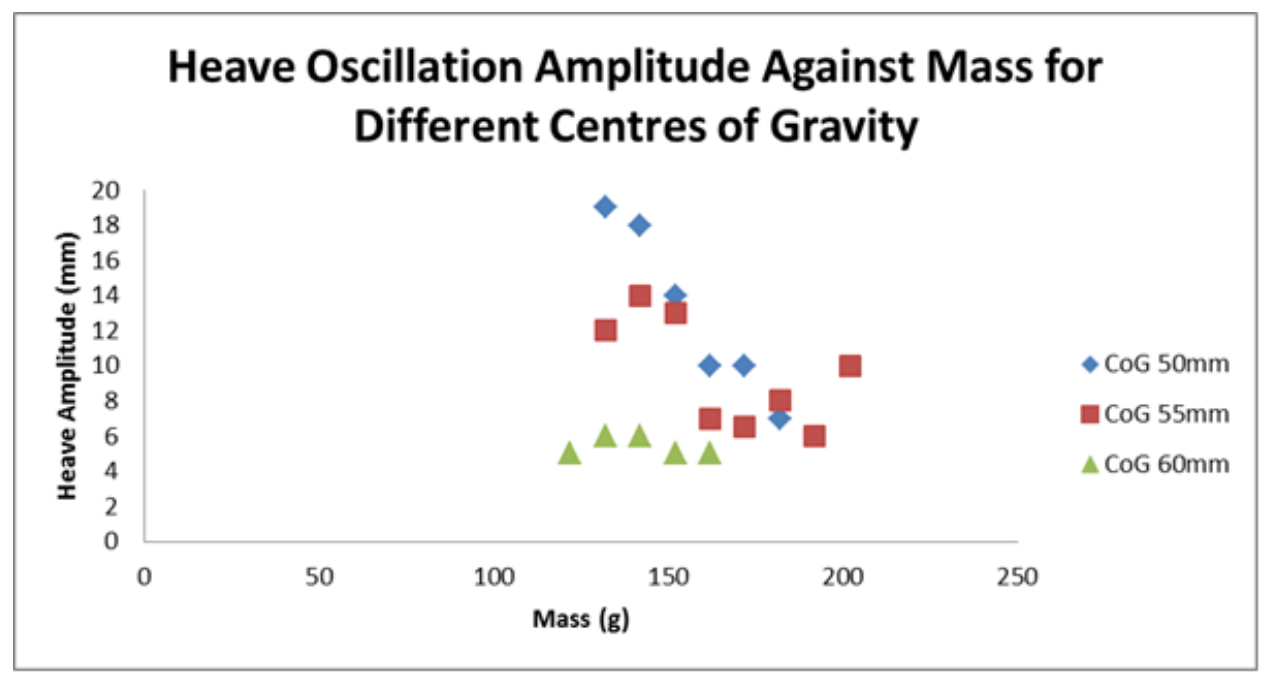

Fig. 12 Heave Amplitude against Mass for Different Centres of Gravity

From Fig. 12 it can be noticed that the best correlation is attained with the Centre of Gravity furthest back. An almost identical relationship with all three data sets is seen with the heave oscillation, a decrease in oscillation amplitude with increasing mass. Again, the furthest forward center of gravity shows almost no change in amplitude with change in mass.

The data may also be used to establish mean trim angle of the hull. This was estimated using the Simulink output graphs. Fig. 13 shows how the mean hull trim angle varies with mass.

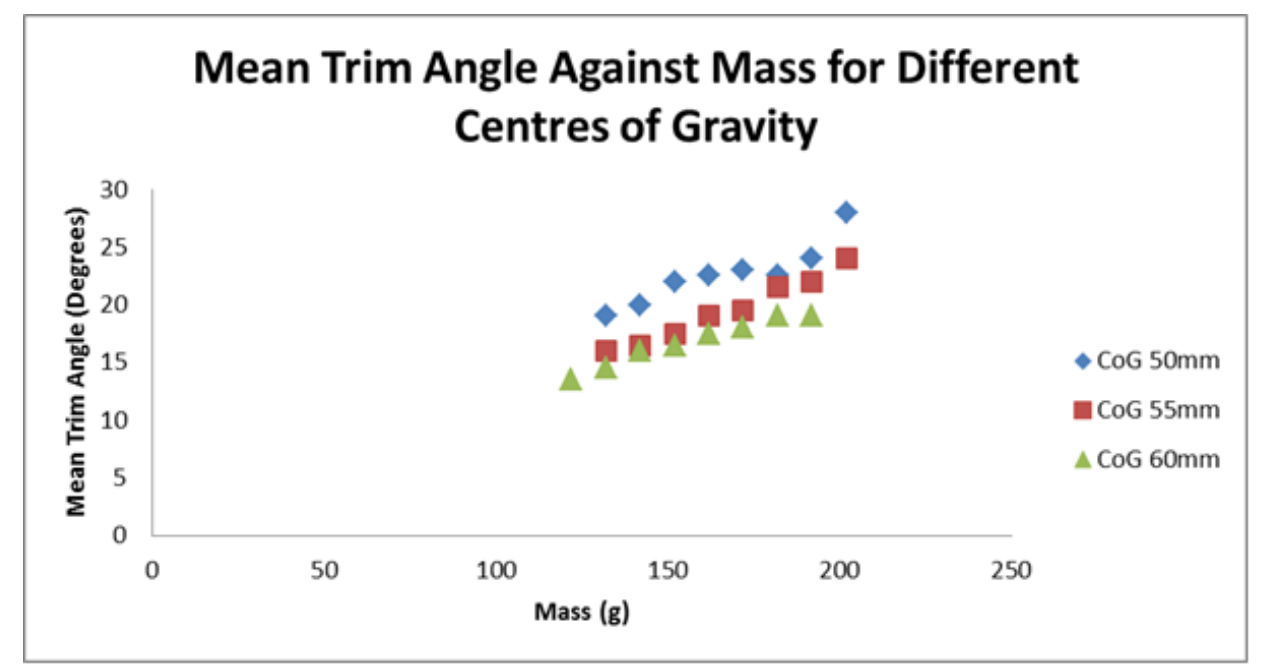

Fig. 13 Mean Trim Angle against Mass for Different Centres of Gravity 
The graph shows that the trim angle increases with increasing mass. Both centers of gravity at $55 \mathrm{~mm}$ and $60 \mathrm{~mm}$ show this to be linear. With the center of gravity at $50 \mathrm{~mm}$, the relationship appears to be linear, but drifts a little as the mass increases. The highest mass is then back on the line.

\section{B. Effect on Oscillation of Flow Velocity}

Testing the effect of flow velocity was done at a single centre of gravity position and mass. Only the velocity was changed. The velocities tested are shown in Table 3.

Table 3 Different Tested Velocities

\begin{tabular}{|l|}
\hline $1.255 \mathrm{~m} / \mathrm{s}$ \\
\hline $1.402 \mathrm{~m} / \mathrm{s}$ \\
\hline $1.483 \mathrm{~m} / \mathrm{s}$ \\
\hline $1.632 \mathrm{~m} / \mathrm{s}$ \\
\hline $1.741 \mathrm{~m} / \mathrm{s}$ \\
\hline $1.870 \mathrm{~m} / \mathrm{s}$ \\
\hline $1.994 \mathrm{~m} / \mathrm{s}$ \\
\hline
\end{tabular}

Qualitative measurements were made during the experiments. It was found that porpoising was not sustained at very low speeds. There was occasional porpoising that occurred erratically at different periods. But sustained porpoising was not achieved until the flow reached $1.632 \mathrm{~m} / \mathrm{s}$.

When recording the footage, an attempt was made to capture these sporadic moments at low speeds, to enable the oscillation to be it analyzed, albeit over a short period.

Fig. 14 shows how the frequency of the oscillation changed with the flow speed. 


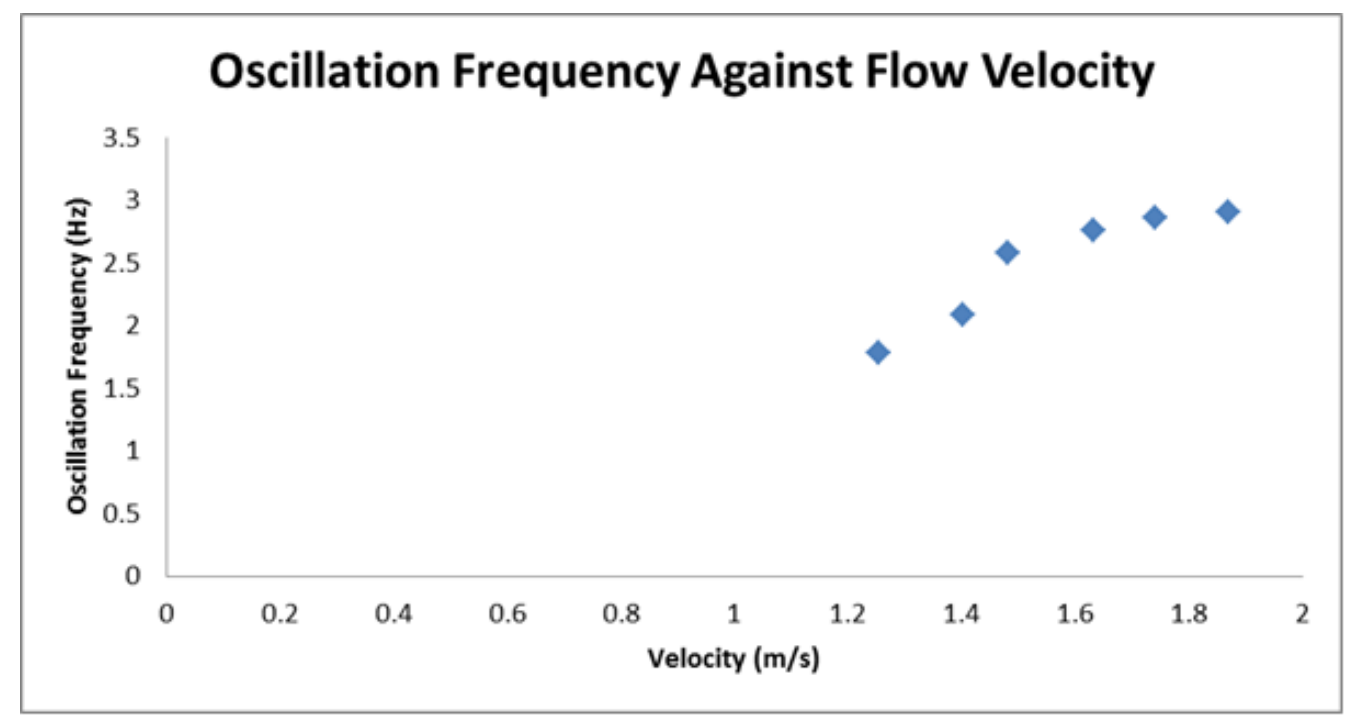

Fig. 14 Oscillation Frequency against Flow Velocity

Fig. 14 shows that oscillation frequency steadily increases with flow velocity. It should be noted that the first two data points are at velocities of $1.255 \mathrm{~m} / \mathrm{s}$ and $1.483 \mathrm{~m} / \mathrm{s}$. Oscillation during these periods was not sustained, however, when it did occur, the data for these points was recorded. No oscillation was found at $1.402 \mathrm{~m} / \mathrm{s}$. There is a slight step jump in the frequency after this point, implying a difference in the mechanics of the oscillation. The last four points are more uniform in this period, again showing the steady increase in the frequency of the oscillation.

Further evidence of the difference between sustained and unsustained oscillation can be seen in Fig. 15. The graph shows how the amplitude of the pitch oscillation varies with flow velocity.

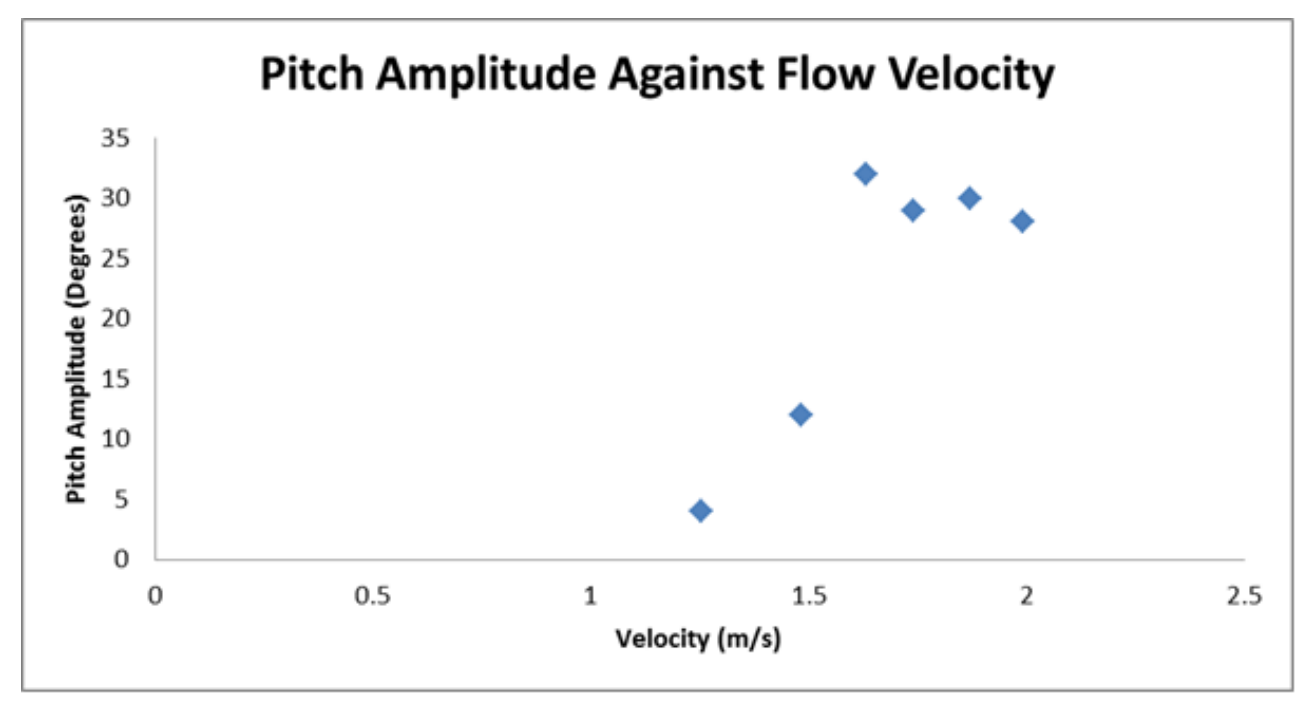

Fig. 15 Pitch Oscillation Amplitude against Flow Velocity 
In this instance, there is again a step jump between the points of sustained oscillation and unsustained oscillation. However, this time the jump is far greater. The first two points are of a very different magnitude of amplitude. Once the velocity reaches $1.632 \mathrm{~m} / \mathrm{s}$, a relationship can be seen. The amplitude of pitch oscillation steadily decreases with an increase in velocity.

A similar trend is repeated in Fig. 16, showing the amplitude of heave oscillation.

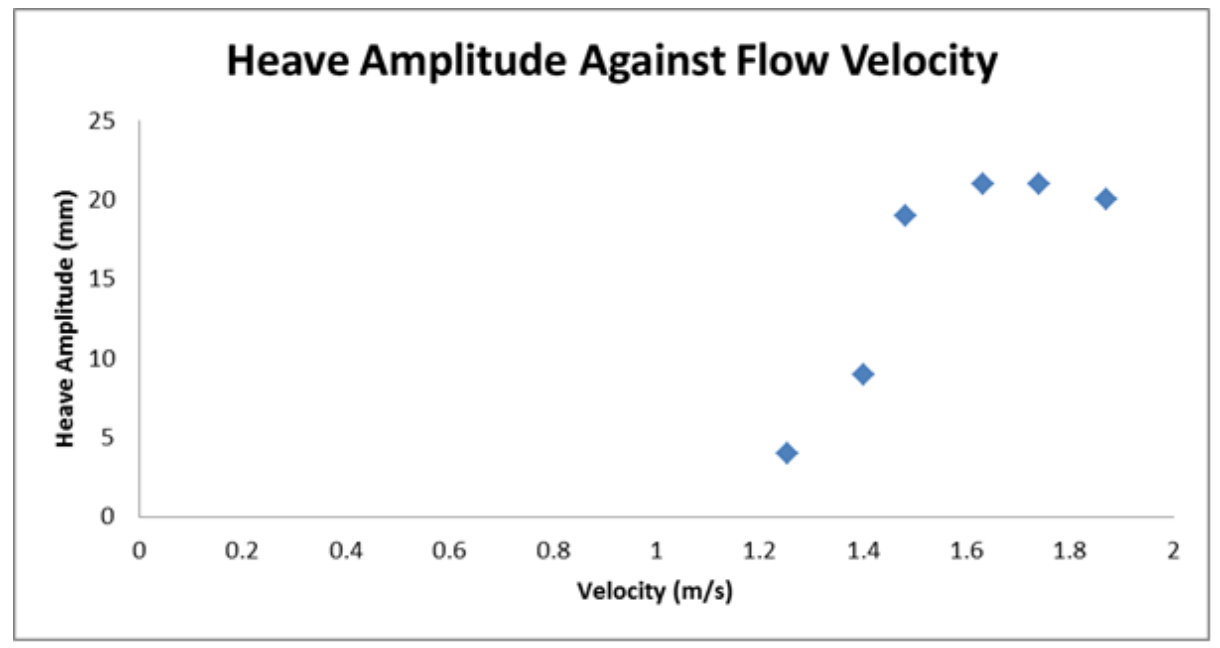

Fig. 16 Heave Oscillation Amplitude against Velocity

It can be noticed in Fig. 16 that a large step jump is seen in amplitude, corresponding to the point where sustained porpoising was observed. The only noticeable difference is that the decrease in amplitude with increase in velocity is less pronounced; only being noticeable in the last three points. Fig. 17 shows how the mean trim angle varies with velocity.

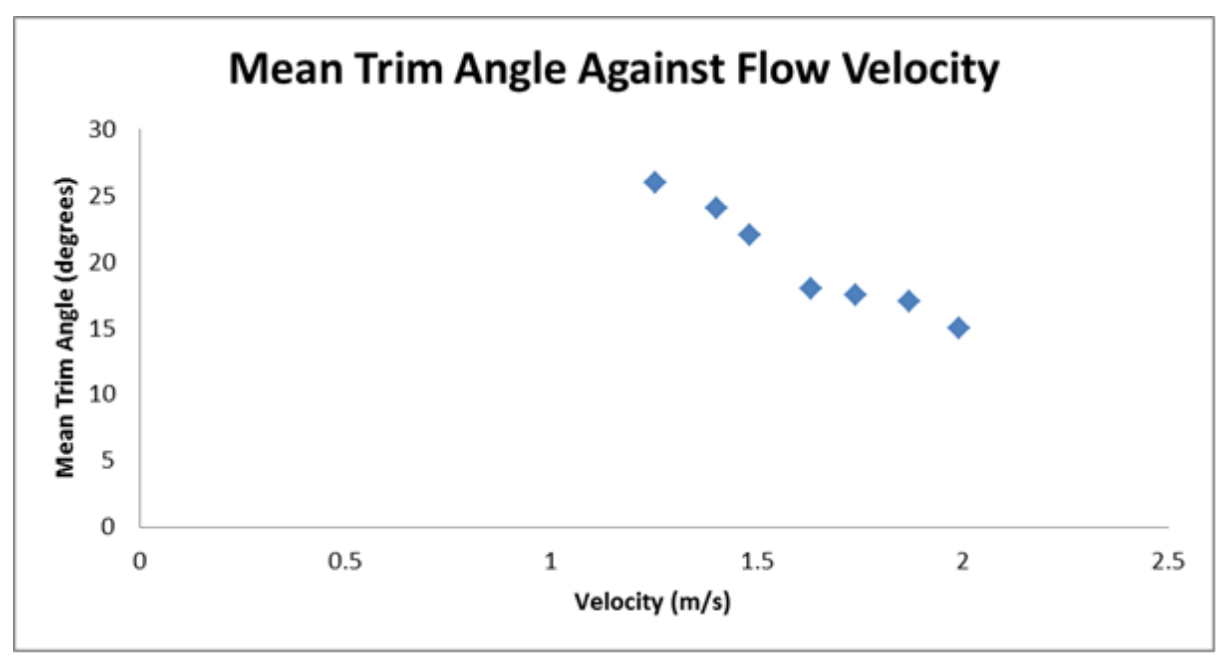

Fig. 17 Mean Trim Angle against Flow Velocity 
The trim angle decreases dramatically with increase in velocity. There is apparently a change in gradient at the point where sustained porpoising was observed.

\section{ANALYSIS}

When looking at the experiment where velocity was changed, it was noted that the oscillation was not sustained at lower speeds. There were however, periods where the oscillation did exist for short periods. It is believed that the oscillation was triggered by fluctuations in the flow.

It is believed that if completely smooth flow was achieved, that the oscillation may not have taken place at all. Referring back to Fig. 15 and Fig. 16, the amplitude of both pitch and heave oscillations was found to vary considerably dependent on whether porpoising was observed to be sustained or not. This can actually be used to define the existence of the phenomenon.

Fig. 18 shows pitch amplitude against velocity, with a bounded region added. This region defines the area where sustained porpoising exists at the lowest velocity; in effect, where the phenomenon begins.

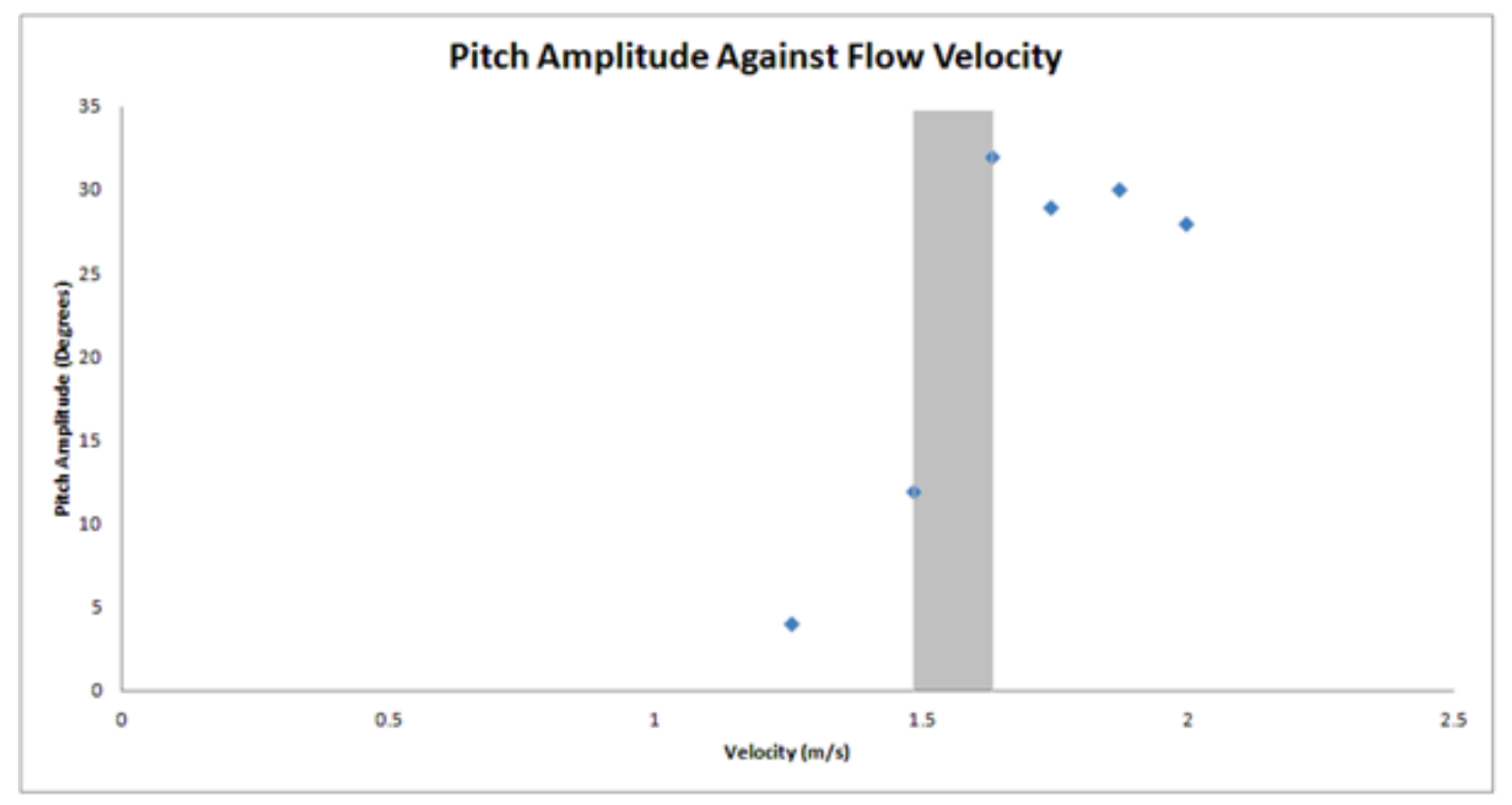

Fig. 18 Region where Sustained Porpoising Occurs for the First Time 
This complies with Savitsky's theory in [5] of the porpoising limit. In order to attempt to quantify this theory, a comparison of the data can be plotted. Fig. 3 shows the porpoising stability limit, as shown in [5-7].

In order to make a comparison between the data provided in Fig. 3 and experimental data, the results must be manipulated into the same form as that shown in [5-7]. Average trim angle was measured in degrees, so this already matches. However, other data taken from the test conditions must be given in terms of the lift coefficient.

The lift coefficient can be obtained from the load on the water, or the hull's weight. This is given by Eq. (3).

$$
C_{L}=\frac{\Delta}{\frac{1}{2} \rho V^{2} b^{2}}
$$

By substituting the test values in at velocities of $1.483 \mathrm{~m} / \mathrm{s}$ and $1.632 \mathrm{~m} / \mathrm{s}$, it is possible to find the lift coefficient and hence, the $\sqrt{C_{L} / 2}$ value shown on Savitsky's graph. The resultant values are shown in Table 4 .

Table 4 Values of trim angle and $\sqrt{C_{L} / 2}$ for points bounding the porpoising limit

\begin{tabular}{|c|c|c|}
\hline Velocity $(\mathrm{m} / \mathrm{s})$ & $\sqrt{C_{L} / 2}$ & Trim Angle \\
\hline 1.483 & 0.3972122 & $22^{\circ}$ \\
\hline 1.632 & 0.3609471 & $18^{\circ}$ \\
\hline
\end{tabular}

The tests were all performed on flat bottomed hulls, meaning deadrise was $0^{\circ}$. By extracting data from Fig. 3, a comparison between Savitsky [5] and the data in Table 4 was carried. It is also necessary extrapolate Savitsky's data so that it reaches high enough trim angles and lift coefficients. The first comparison show that the vicinity in which sustained porpoising was achieved in the experiment is within the same approximate vicinity as that established in [5]. However, there are still a number of discrepancies. The line between the two experimental points appears to be at a similar gradient to that extrapolated from Savitsky's data. This is unusual, as the points represent a value that if correct, would be one either side of this line. Being nearly parallel makes this possibility difficult to achieve.

The gradient of the line between the two points is slightly steeper than Savitsky's. This means that even if the points were to fall either side, it would leave the Non-oscillating position in the realm of porpoising, and the oscillating position in that of non-porpoising. One possibility is that at the higher trim angles and lift coefficients the experiment takes place at, Savitsky's data is no longer applicable. It might be that porpoising stability limit line 
gradient has a tendency to increase at higher values. Fig. 19 shows a comparison of porpoising stability after corrections between Savitsky's predictions and the experimental data.

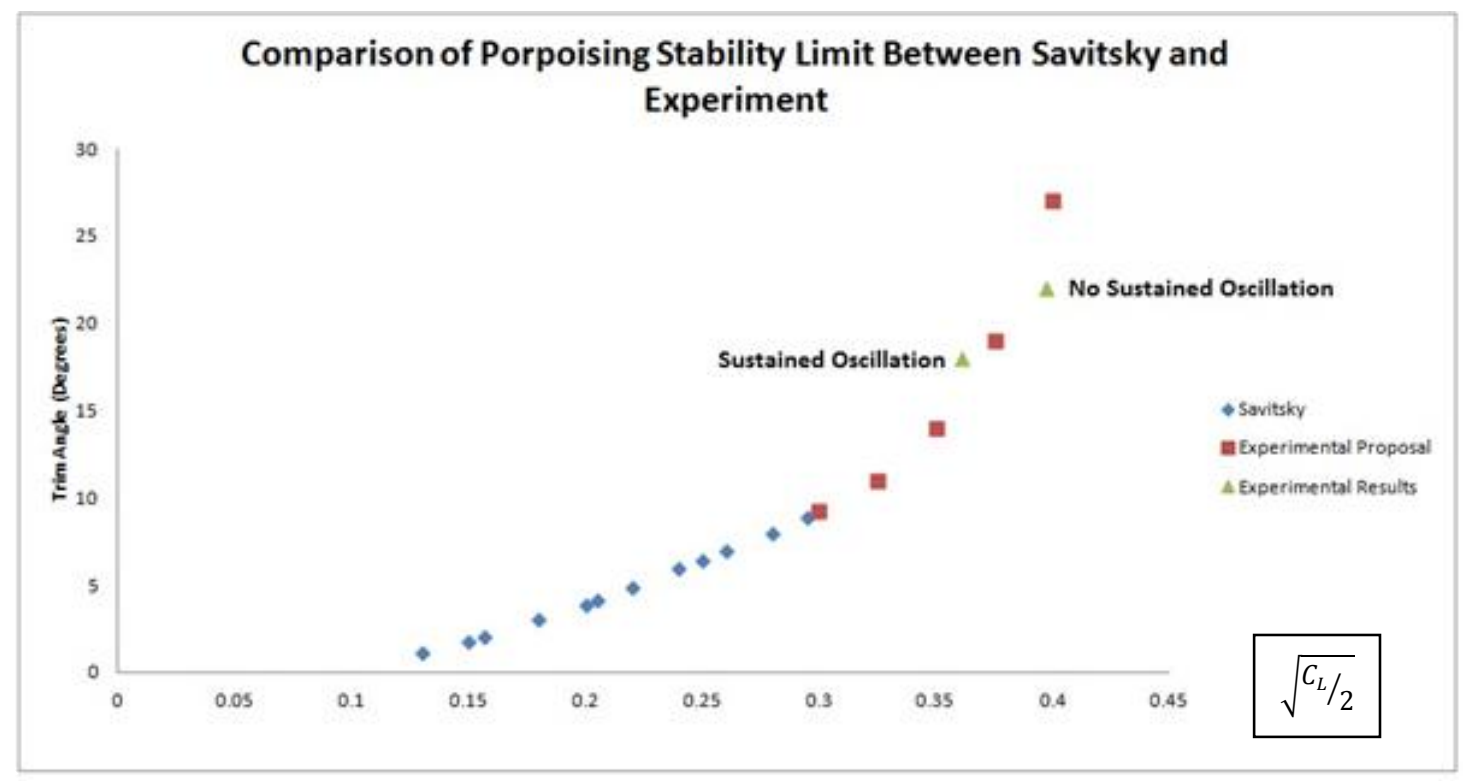

Fig. 19 Data Comparison showing Porpoising Stability Limit

\section{CONCLUSION}

The dynamic motion of hydroplaning hull forms has been experimentally tested using a shallow water flume for the first time. The equipment and the experimental method developed for this research have led to an analysis of a hull porpoising in a supercritical channel. From the experimental point of view, this enables a number of conclusions to be drawn.

- The porpoising motion can be captured using an experimental method derived from the store separation freedrop.

- The porpoising limit is a well-defined region, where unsustained oscillation turns into sustained oscillation.

- Porpoising motion approximates a sinusoidal curve.

- Acceleration vertically in heave is greater upwards than downwards 
But the main conclusion is that porpoising of a hull can be instigated using a shallow flume with supercritical flow. The experimental method developed from the store separation freedrop must still be improved, especially the video capture presents numerous problems when recording through a glass window in a wet environment as splashes distort the footage but this can be overcome.

\section{References}

[1] Stout, E.G., "Experimental Determination of Hydrodynamic Stability," Journal of the Aeronautical Sciences (Institute of the Aeronautical Sciences), Vol. 7, No. 2, 1940, pp. 55-61.

[2] Stout, E.G., Development of High-speed Water-Based Aircraft," Journal of the Aeronautical Sciences (Institute of the Aeronautical Sciences), Vol. 17, No. 8, 1950, pp. 457-480.

[3] Van Dyck, R., “Seaplanes and the Towing Tank,” Advanced Marine Vehicles Conference, 1989, 10.2514/6.1989-1533.

[4] Perring, W. G. A. and Glauert, H., "Stability on the Water of a Seaplane in the Planing Condition," Aeronautical Research Committee, Reports and memoranda, 1493, 1932.

[5] Savitsky, D., "Hydrodynamic Design of Planing Hulls,” Marine Technology, Vol.1, No.1, October 1964, pp.71-95.

[6] Savitsky, D., and Ward, D., "Procedures for Hydrodynamic Evaluation of Planing Hulls in Smooth and Rough Water," Marine Technology, Vol.13, No.4, October 1976, pp.381-400.

[7] Savitsky, D., and Ross, E., "Turbulent Stimulation in the Boundary Layer of Planing Surfaces," Stevens Institute of Technology, Davidson Laboratory, Report 44, 1952.

[8] Martin, M., "Theoretical Determination of Motion of High-Speed Planing Craft in Waves," David W. Taylor Naval Ship Research and Development Center (TNSRDC) Report 76-0069, Apr 1976.

[9] Schroder, P., “The Take-off of Seaplanes, based on a New Hydrodynamic Reduction Theory,” National Advisory Committee for Aeronautics, NACA-TM-621, May 1931.

[10] Sottorf, W., "Experiments With Planing Surfaces," National Advisory Committee for Aeronautics,Technical Memorandum $661,1932$.

[11] Sottorf, W., "Systematic Model Researches on the Stability Limits of the DVL Series of Float Designs," National Advisory Committee for Aeronautics, Technical Memorandum 1254, 1949.

[12] Locke, F.W.S., "General Porpoising Tests of Flying Boat Hull Models,” National Advisory Committee for Aeronautics, Advanced Restricted Report, 1943.

[13] Davidson K. S. M. and Locke, F. W. S. Jr., "Some analyses of systematic experiments on the resistance and porpoising characteristics of flying-boat hulls," National Advisory Committee for Aeronautics, Advanced Restricted Report 3I06, September 1943. 
[14] Day, J. P., and Haag, R. J., "Planing Boat Porpoising," PhD Dissertation, Institute of Naval Architecture, 1952.

[15] Payne, P.R., "Coupled Pitch and Heave Porpoising Instability in Hydrodynamic Planing," Journal of Hydronautics, Vol. 8, No. 2 , Apr 1974.

[16] Payne, P.R., "Errata-Coupled Pitch and Heave Porpoising Instability in Hydrodynamic Planing", Journal of Hydronautics, Vol.9: 0048b, 1975, 10.2514/3.63018

[17] Arnold, R.J., and Epstein, C.S., "Store Separation Flight Testing", AGARD Flight Test Techniques Series, AGARD-AG300-Vol.5, April 1986. 